Endocrinol. Japon. 1961, 8 (3), 210 216

\title{
ON THE FUNCTIONAL CORRELATION BETWEEN SALIVARY GLANDS AND OTHER ENDOGRINE ORGANS IV.

\author{
THE EFFECT OF ANTITHYROID DRUGS ON THE THYMUS \\ AND SALIVARY GLANDS OF THE RAT AND THE STUDY \\ ON THE RELATION BETWEEN THESE TWO ORGANS
}

\author{
(STUDIES ON THE PHYSIOLOGICAL CHEMISTRY \\ OF THE SALIVALY GLANDS LXII*)
}

\author{
YOSOJI ITO, JUN KAWADA AND MUNETSUGU KURATA \\ Department of Physiological Chemistry, Faculty of Pharmaceutical \\ Sciences, University of Tokyo, Tokyo
}

It has been shown that some antithyroid drugs inhibit the weight-increase of the salivary glands in rats, especially submaxillary glands, and also cause almost invariably marked atrophy of the thymus (Ito et al., 1960). But a relation between the salivary glands and the thymus is quite unknown. To elucidate preliminary this problem, the present report deals with the studies as follows; the re-investigation of the effect of antithyroid drugs on male and female rats, the influence of the thymus after treatment with corticosteroid or testosterone on the salivary glands, and inversely, the effect of the duct-ligation or extirpation of the salivary glands on the thymus.

\section{MATERIALS AND METHODS}

Animals The animals used were albino rats of the Wistar strain of both sexes. All animals were maintained on CLEA-pellets (CE-2) and given drugs or operated at 8 weeks of age. Each group consisted of $6 \sim 8$ animals.

Administration of drugs As antithyroid drugs the following substances were given in drinking water starting from 8 weeks of age for 3 weeks; thiocyanate (KSCN) $0.5 \%$, perchlorate $\left(\mathrm{KClO}_{4}\right) 1 \%$, thiouracil (TU) $0.2 \%$, methylthiouracil (MTU) $0.1 \%$, propylthiouracil (PTU) $0.1 \%$ and methylmercaptoimidazole (MMI) $0.05 \%$. In the case of combined administration of TU and $\mathrm{KClO}_{4}$, concentration of each substance was as indicated above. Hydrocortisone acetate was used as a corticosteroid. It was daily injected subcutaneously for 2 weeks at a dose level of $400 \mu \mathrm{g} / \mathrm{rat} / \mathrm{day}$ in a low dose group, and $2 \mathrm{mg} / \mathrm{rat} / \mathrm{day}$ in a high dose group. Testosterone propionate in oil was given by subcutaneous injection for 2 weeks in 2 doses, $200 \mu \mathrm{g} /$ rat daily and $1 \mathrm{mg} /$ rat every other day.

Duct-ligation and extirpation of the salivary glands The ducts of the submaxillary glands of both sides were exposed by an incision in the skin at the cervical region. After having been carefully severed from the vessels and nerves of the submaxillary glands, they were ligated. Animals were sacrificed 5 days and 9 days after duct-ligation. The salivary glands of 2 groups of animals were removed. From one group only the submaxillary plus sublingual glands were ectomized, and of the other total salivary-ectomy was performed. In both groups, rats were autopsied at the 3 weeks end of the experimental period.

Received for publication July 10, 1961.

* LXI : Asano, H. (1961). Endocrinol. Japon. 8, 205. 


\section{RESULTS AND DISGUSSION}

Effect of antithyroid drugs The effect of antithyroid drugs on the weight of organs are given by Table 1 . In the table, $\mathrm{C}_{\mathrm{I}}$ indicates the initial control group at 8 weeks of age and $C_{F}$ does final control group at the end of 3 weeks period of treatment, namely 11 weeks of age. Weight of the salivary glands, thymus, thyroid, adrenal, pituitary and the liver was studied. As summarized in Table 1-A, MTU, PTU and MMI markedly inhibited the weight-increase of the submaxillary glands. The atrophy of the thymus was evident in the group to which MMI and PTU were given.

Not any change was found on the salivary glands and the thymus in the group given KSCN as compared with the control. Although hyperplasia of the thyroid was not evident in this dose level of KSCN, an inhibition of the iodine metabolism in the thyroid might be inferred from the result of $\mathrm{KClO}_{4}$ administration as previously reported (Ito et al., 1961). Similar results were obtained from the female animals to which MMI and KSCN were given as summarized in Table 1-B. Many reports have been presented as to the sexual dimorphism of the salivary glands (Lacassagne, 1940; Leblond and Grad, 1948 ; Gabe, 1955). But, the effect of antithyroid drugs on the weight of the salivary glands and thymus was almost equally observed in both sexes. Table 1-G shows the influence of $\mathrm{TU}$ and $\mathrm{KClO}_{4}$ administration on the male rats. The weight increase of the submaxillary glands was inhibited in all cases, but the effect of $\mathrm{KClO}_{4}$ was only slight and that of the combined administration was the most potent. Although no change was observed on the parotid glands in this study, it has been previously reported that the effect of antithyroid drugs on the parotid glands is often indefinite. The atrophy of the thymus was markedly found by the administration of $\mathrm{TU}$ and $\mathrm{TU}$ plus $\mathrm{KClO}_{4}$, but not by $\mathrm{KClO}_{4}$. It seems interesting from the view point of the hormonal mechanism of goiter formation that no hyperplasia of the thyroid was observed in the group of combined administration.

Summarizing the above and the already presented data (Ito et al., 1960 ; Ito et al., 1961), anionic antithyroid substances such as thiocyanate and perchlorate, have little influence upon the weight-increase of the salivary glands inspite of their depressive effect on the thyroidal iodide metabolism. The atrophy of the thymus is not also observed by the administration of this type of antithyroid drugs. On the contrary, the thioureylene-type antithyroid drugs such as TU, MTU, PTU and MMI markedly influence the weight of the salivary glands, especially the submaxillary glands and thymus.

Effect of corticosteroid and testosterone Marked atrophy of the thymus and the inhibition of weight-increase of the salivary glands were observed at the same time by the administration of some antithyroid drugs. Although this change in the thymus might be explained by hypofunction of the thyroid, there are differences of opinions regarding the relation between the thyroid and thymus (Carriére et al., 1938; Frenkel-Conrat et al., 1940; Reinhardt and Weinman, 1942 ; Gregoire, 1949; Boatman et al., 1951; Dougherty, 1952). A possibility also exists that antithyroid drugs directly influence the thymus. It has been found that 


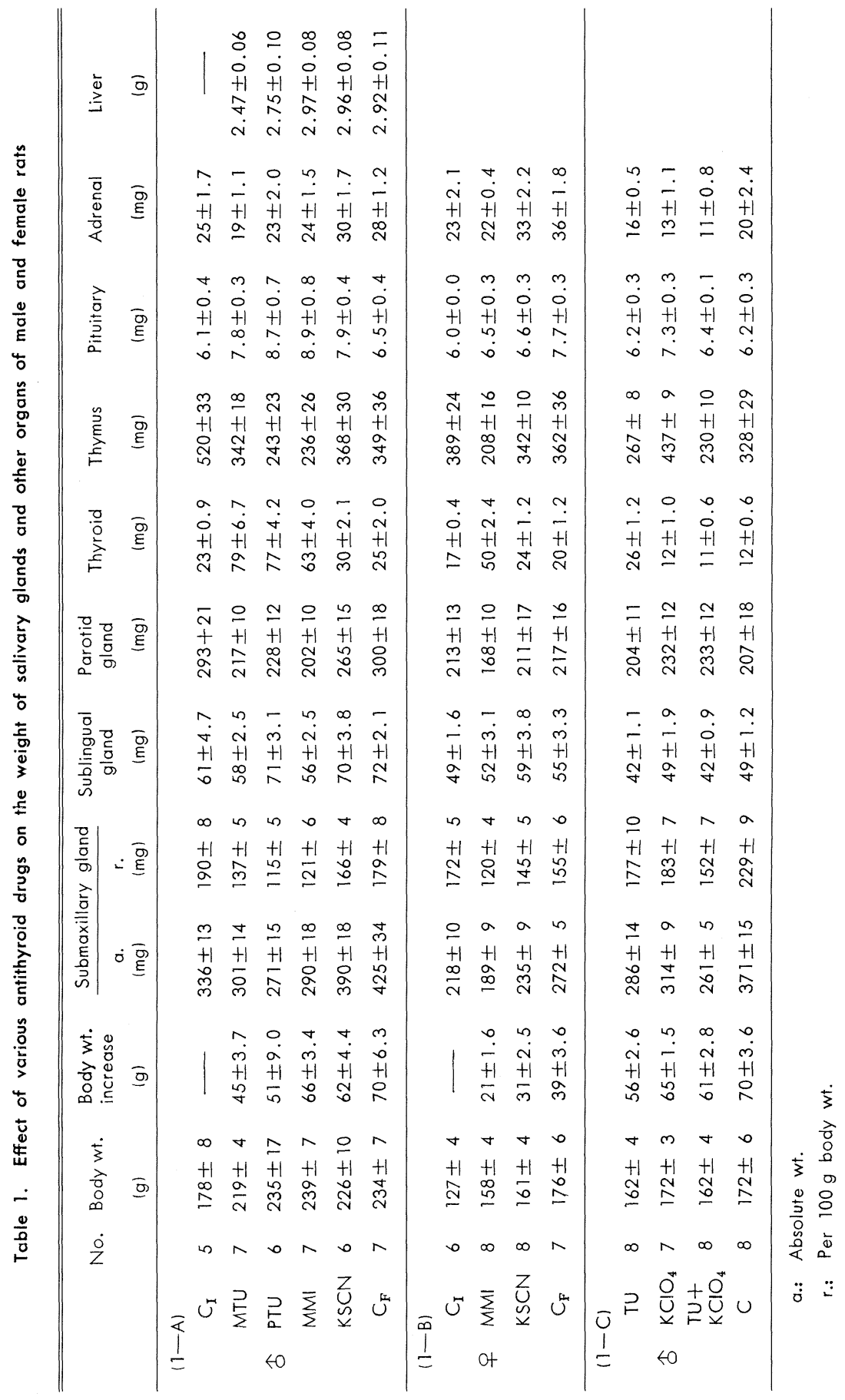




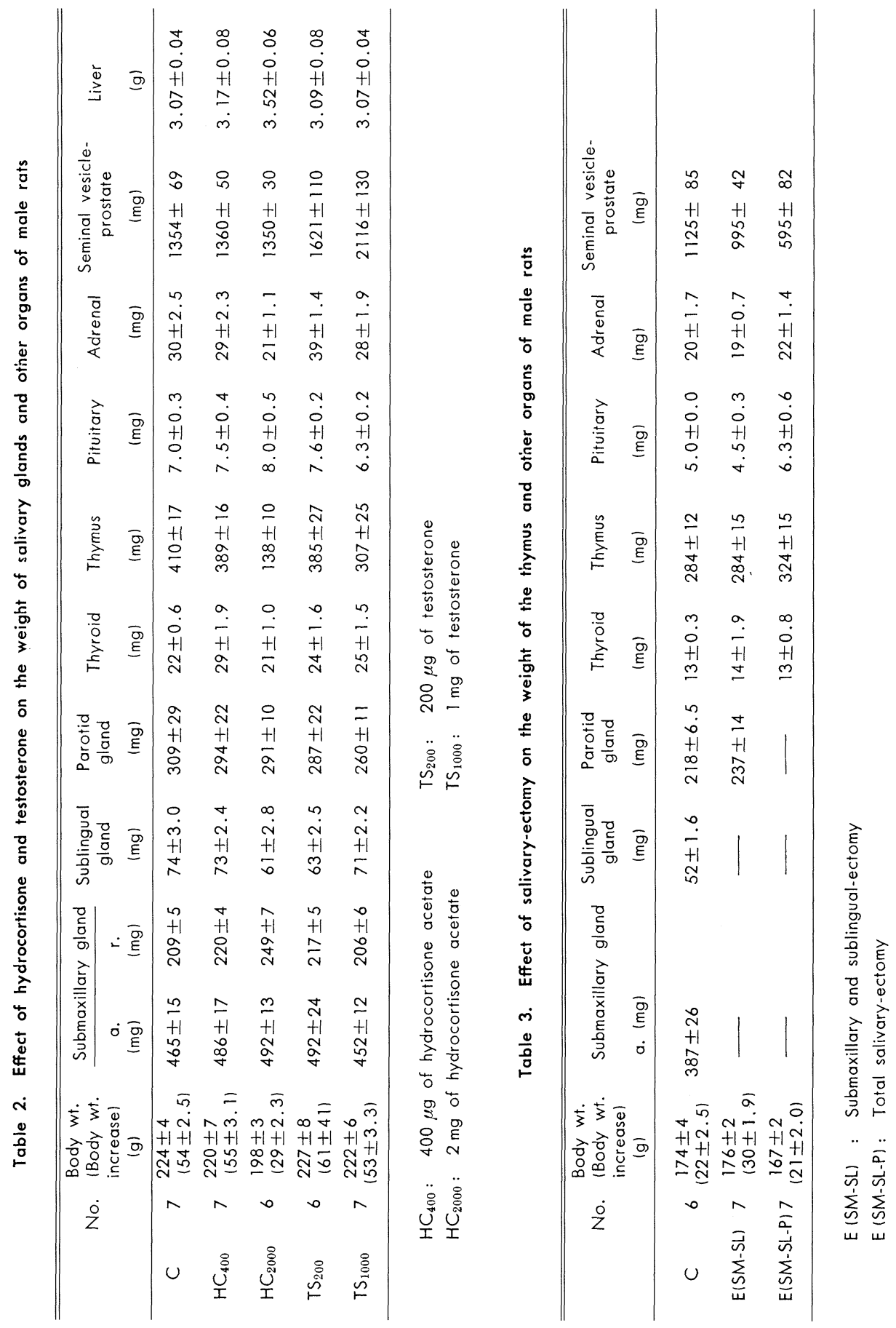




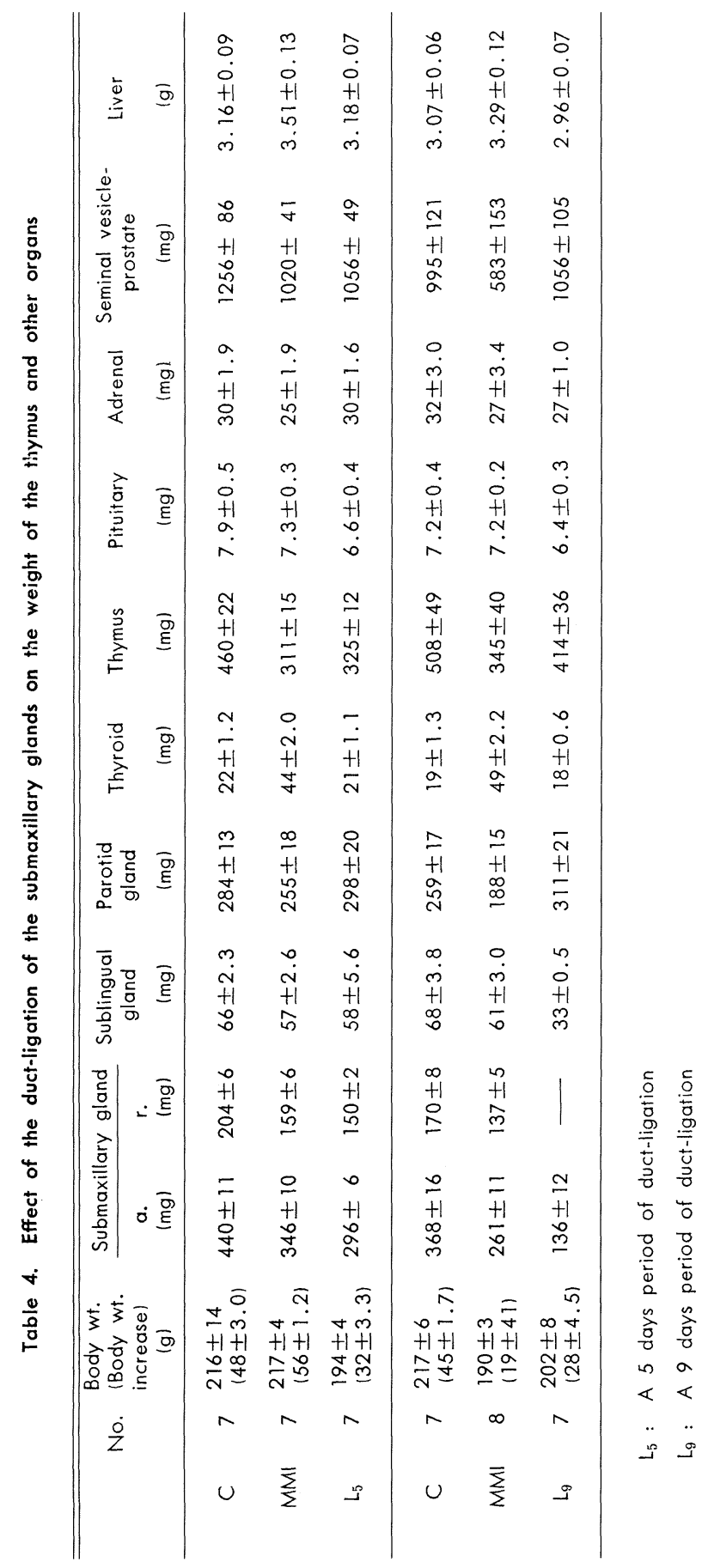


corticosteroids (Ingle, 1940; Antopol, 1950; Ingle and Meeks, 1952) and sexhormones (Korenchevsky et al, 1932; Li and Evans, 1948 ; Money et al., 1952) result in a atrophy of the thymus. Therefore an experiment was made to study whether the atrophy of the thymus by these substances become a direct factor of the change in the weight of the salivary glands. Table 2 summarizes the effect of hydrocortisone and testosterone on the weight of some organs. The effectiveness of each substance was recognized from the atrophy of the adrenal or marked weight-increase of the seminal vesicle and prostate respectively. Although marked atrophy of the thymus was observed in high dose groups, no significant change occurred in the salivary glands as compared with the control group. From the authors' experiments, no evidence has been obtained here as to an increasing rate of secretion of corticosteroids or testosterone. Therefore, biological significance of the method inducing atrophy of the thymus by these hormonal substances is not always related to the hormonal change in the animals caused by the administration of antithyroid drugs. But it is inferred that the atrophy of the thymus is not an essential factor inducing inhibition of weightincrease of the salivary glands.

Effect of extirpation and duct-ligation of the salivary glands In contrast with the above study, the weight of the thymus after a given period of salivary-ectomy or duct-ligation of the salivary glands was compared to solve the question as to whether the hypofunction of the salivary glands is related to the atrophy of the thymus. As shown in Table 3, no difference was recognized in the weight of the thymus at any stage of extirpation of the salivary glands. The thyroid glands also did not change in organ weight. Table 4 summarized the influence of duct-ligation of the submaxillary glands. During a 5 days period of ligation, the submaxillary glands decreased in weight to the nearly same extent as observed in the MMI administered group and the marked atrophy of the thymus was recognized. But, after 9 days of ligation, the atrophy of the thymus was rather slight inspite of almost complete degeneration of the submaxillary glands. If one accepts the direct relationship between hypofunction of the submaxillary glands and the occurence of atrophy of the thymus, the latter result is contradictory to the former. Therefore, it might be inferred that the salivary hypofunction does not play a role in the atrophy of the thymus and the change of the weight in both organs induced by the administration of antithyroid drugs is an independent phenomenon from each other.

\section{SUMMARY}

Marked inhibition of weight-increase in the salivary glands and atrophy of the thymus were simultaneously observed in both male and female rats by the administration of the thioureylene-type antithyroid drugs. But considering the fact that the atrophy of the thymus experimentally induced by the administration of corticosteroid or testosterone did not result in a weight-decrease in the salivary glands and that, inversely, atrophy of the thymus was not always observed during a given period of salivary-ectomy or duct-ligation of the submaxillary glands, it seems, that there is no direct relationship between the thymus and 
the salivary glands. Hence, the marked change in the weight of both organs observed in the administration of an antithyroid drug is considered to be independent of each other.

\section{AGKNOWLEDGEMENT}

The authors wish to thank to the Chugai Pharmaceutical Co., Ltd. for supplying the chemicals which made this experiment possible.

\section{REFERENCES}

Antopol, W. (1950). Proc. Soc. Exptl. Biol. Med. 73, 262.

Boatman, J. B., J. H. Sunder, C. Russ and M. Campbell (1951). Ibid. 78, 250.

Carriére, G., J. Morel and P. -J. Geneste (1938). Compt. rend. soc. biol. 128, 1151.

Dougherty, T. F. (1952). Physiol. Rev. 32, 379.

Fraenkel-Conrat, H. L., D. L. Meamber, M. E. Simpson and H. M. Evans (1940). Endocrinology 27, 605.

Gabe, M. (1955). Compt. rend. soc. biol. 149, 223.

Gregoire, G. H. (1949). J. Endocrinol. 6, 14.

Ingle, J. D. (1940). Proc. Soc. Exptl. Biol. Med. 49, 174.

Ingle, J. D. and R. C. Meeks (1952). Am. J. Physiol. 170, 67.

Ito, Y., J. Kawada and M. Kurata (1960). Endocrinol. Japon. 7, 157.

Ito, Y., J. Kawada and M. Kurata (1961). Ibid. 8, 1.

Korenchevsky, V., M. Denninson and R. Shalit (1932). Biochem. Z. 26, 1306.

Lacassagne, A. (1940). Compt. rend. soc. biol. 133, 180.

Leblond, C. P. and B. Grad (1948). Anat. Record 100, 750.

Li, C. H. and H. M. Evans (1948). Recent Progr. in Hormone Research 3, 3.

Money, W. L., J. Fager and R. W. Rawson (1952). Cancer Research 12, 206.

Reinhardt, W. O. and P Wainman (1942). Proc. Soc. Exptl. Biol. Med. 49, 257. 